\title{
CHEMISTRY, NANOSTRUCTURE AND MAGNETIC PROPERTIES OF
}

\section{Co-Ru-B-O NANOALLOYS}

\section{G.M. Arzac ${ }^{a}$ T.C. Rojas ${ }^{a^{*}}$, L.C. Gontard ${ }^{a}$, L.E. Chinchillab ${ }^{b}$ E. Otal ${ }^{c, d}$, P. Crespo $^{\mathrm{e}}$, A. Fernández ${ }^{\mathrm{a}}$}

${ }^{a}$ Instituto de Ciencia de Materiales de Sevilla (CSIC-Univ. Sevilla), Avda. Américo Vespucio 49, 41092-Sevilla, Spain.

${ }^{\mathrm{b}}$ Departamento de Ciencia de Materiales, Ingeniería Metalúrgica y Química Inorgánica, Facultad de Ciencias, Universidad de Cádiz,11510 Puerto Real, Cádiz, Spain.

${ }^{\mathrm{c}}$ Division of Porous Materials, UNIDEF, CITEDEF, CONICET, S. J. B de la Salle 4397, Villa Martelli (B1603ALO), Buenos Aires, Argentina.

${ }^{d}$ Laboratory for Materials Science and Technology, FRSC-UTN, Av. Inmigrantes 555, Río Gallegos (9400), Argentina.

e Instituto de Magnetismo Aplicado (RENFE-UCM-CSIC), P.O. Box 155, 28230 Las Rozas, Madrid, Spain and Departamento de Física de Materiales, Universidad Complutense, Madrid, Spain

*Corresponding author: tcrojas@icmse.csic.es

\section{Abstract}

In our previous works, $\mathrm{Co}-\mathrm{B}-\mathrm{O}$ and $\mathrm{Co}-\mathrm{Ru}-\mathrm{B}-\mathrm{O}$ ultrafine powders with variable $\mathrm{Ru}$ content $\left(\mathrm{x}_{\mathrm{Ru}}\right)$ were studied as catalysts for hydrogen generation through sodium borohydride hydrolysis. These materials have shown a complex nanostructure in which small Co-Ru metallic nanoparticles are embedded in an amorphous matrix formed by Co-Ru-B-O based phases and $\mathrm{B}_{2} \mathrm{O}_{3}$. Catalytic activity was correlated to nanostructure, surface and bulk composition. 
However, some questions related to these materials remain unanswered and are studied in this work. Aspects as: 3D morphology, metal nanoparticle size, chemical and electronic information in the nanoscale (composition and oxidation states), and the study of the formation or not of a $\mathrm{Co}_{\mathrm{x}} \mathrm{Ru}_{1-\mathrm{x}}$ alloy or solid solution are investigated and discussed using XAS (X ray Absorption Spectroscopy) and Scanning Transmision Electron Microscopy (STEM) techniques. Also magnetic behavior of the series is studied for the first time and the structure-performance relationships discussed. All Co-containing samples exhibited ferromagnetic behavior up to room temperature while Ru-B-O sample is diamagnetic. For the $\mathrm{x}_{\mathrm{Ru}}=0.13$ sample, an enhancement in the Hc (coercitive field) and Ms (saturation magnetization) is produced with respect to the monometallic Co-B-O material. However this effect is not observed for samples with higher $\mathrm{Ru}$ content. The presence of: the $\mathrm{Co}_{\mathrm{x}} \mathrm{B}$-rich (cobalt boride) amorphous ferromagnetic matrix, very small metal nanoparticles $\left(\mathrm{Co}\right.$ and $\left.\mathrm{Co}_{\mathrm{x}} \mathrm{Ru}_{(1-\mathrm{x})}\right)$ embedded in the matrix, and the antiferromagnetic $\mathrm{CoO}$ phase in (for the higher $\mathrm{Ru}$ content sample, $\mathrm{x}_{\mathrm{Ru}}=0.7$ ), explain the magnetic behavior of the series.

\section{Keywords}

Co-Ru-B-O, ultrafine powders, nanostructure, Electron Tomography, EELS, XAS, magnetic properties

\section{1-Introduction}

The depletion of fossil fuels together with the environmental impact related to the emission of carbon dioxide and other contaminants makes necessary the research on new energy sources.

[1] In this context, $\mathrm{H}_{2}$ appears as a clean energy carrier with a high energy density (142MJ.kg-1 while for liquid hydrocarbons is $47 \mathrm{MJ}^{-\mathrm{kg}^{-1}}$ ). [2] The development of a hydrogen economy faces challenges related to $\mathrm{H}_{2}$ production (preferentially from renewable resources), transport and storage. For chemical hydrogen storage, great efforts have been made in these years to develop suitable materials with high gravimetric and volumetric density. In this direction, boron based hydrides are very attractive because of the combination of the lightweight of B and their high 
hydrogen content [3]. Sodium borohydride (SB) is one of the most studied because releases hydrogen safely through its hydrolysis reaction (1) with a high potential hydrogen storage capacity $(10.8 \%$, but usually lower in experimental conditions due to the formation and precipitation of hydrated borates) [3-7]. Also methanolysis (reaction of SB with methanol) and the use of methanol-water mixtures were proposed as efficient methods to produce hydrogen from sodium borohydride with promising hydrogen storage capacity [8].

$$
\mathrm{NaBH}_{4}+2 \mathrm{H}_{2} \mathrm{O} \rightarrow 4 \mathrm{H}_{2}+\mathrm{NaBO}_{2}
$$

Uncatalysed, reaction (1) is very slow. For this reason, many acid and metal catalysts have been tested and/or prepared in these years [4-6]. Most proposed systems for hydrogen generation through (1) are based on the addition of stabilized (on sodium hydroxide) SB solutions to a certain catalyst or by addition of water to a mixture of solid SB and catalyst. [4-6, 8] Cobalt is definitely the most studied metal catalyst because of its cost effectiveness [9-11]. Co based catalysts have been tested and/or prepared in a wide of range of forms, from the simplest $\mathrm{CoCl}_{2} 6 \mathrm{H}_{2} \mathrm{O}$ salt to metallic cobalt, cobalt oxides and also alloyed with another elements [1217]. Co-B based nanoalloys are the most employed in literature [9-11]. Reaction of a cobalt precursor with sodium borohydride in aqueous medium leads to the formation of ultrafine and usually amorphous powders (Co-B materials) with enhanced activity not only for reaction (1) but also for many organic reactions [9-11, 18-19]. Despite being prepared and used in a good number of papers, the exact nature of these nanoalloys is still under intense discussion [9-11, 18]. Their amorphous and/or nanocrystalline character, their compositional complexity and the wide range of reaction conditions reported in literature, make difficult the study and comparison of reported results. Recently, we studied a Co-B-O and a series of Co-Ru-B-O materials as catalysts for reaction (1) [20-21]. We employed STEM/HAADF (High Angle Annular Dark Field) and STEM/EELS (Electron Energy Loss Spectroscopy) techniques together with XPS (X-Ray Photoelectron Spectroscopy), XRD (X-Ray Diffraction), ICP (Inductive Coupling Plasma), to give a structural and chemical view of the Co-B-O material and Co-Ru-B-O series at the micro and nanoscale [20-21]. These materials have shown a complex nanostructure 
characterized by the formation of very small metallic nanoparticles embedded in an amorphous matrix. The Co-B-O material contains Co nanoparticles embedded in a matrix composed of $\mathrm{Co}_{\mathrm{X}} \mathrm{B}$ (cobalt boride), $\mathrm{B}_{2} \mathrm{O}_{3}$ and $\mathrm{Co}-\mathrm{B}-\mathrm{O}$ amorphous phases. The presence of interstitial boron in Co nanoparticles was proposed [20]. For the Co-Ru-B-O series, the Co-containing samples, present a microstructure composed of 20-40 $\mathrm{nm}$ size grains which contain tiny metallic (Co- $\mathrm{Ru})$ nanoparticles embedded in an amorphous matrix constituted by Co-Ru-B-O phases. A veil of $\mathrm{Co}\left(\mathrm{BO}_{2}\right)_{2}$ is surrounding all the structure which tends to decrease in thickness and coverage degree with $\mathrm{Ru}$ content. For the Ru-B $\left(\mathrm{x}_{\mathrm{Ru}}=1\right)$ sample there is a drastic decrease in boron content which produces a change in nanostructure characterized by an abrupt increase in particle size respect to the rest of the series. In that paper, we proposed a structural model that depicted a representation of the nanostructure and composition of the series [21]. This structural model was adequate for a qualitative explanation of the enhancement in catalytic activity of the Co-RuB-O powders respect to the monometallic Co-B-O and Ru-B-O materials [21]. However, some questions related to these materials remain unanswered. The study of metal nanoparticle size, chemical composition of the matrix in the nanoscale, and the formation or not of a $\mathrm{Co}_{\mathrm{x}} \mathrm{Ru}_{1-\mathrm{x}}$ alloy or solid solution was not done before. These studies could be very important for a full comprehension of catalytic properties. Furthermore, the magnetic properties of these nanoalloys are interesting and were not studied before. For these reasons, in this work the Co-Ru-B-O series was deeply studied employing STEM techniques together with XAS (XRay Absroption Spectroscopy) for a full chemical and structural characterization. Also magnetic properties of these materials were studied for the first time. Nanostructure, composition, electronic structure and magnetism are correlated discussed along the Co-Ru-B-O series by the integration of these characterization techniques giving new insights into the study of the cobalt-ruthenium-boron interactions in the nanoscale.

\section{2- Experimental}

\subsection{Sample preparation}


Ultrafine Co-Ru-B-O powder materials were prepared as previously by chemical reduction of an aqueous solution of $\mathrm{CoCl}_{2} \cdot 6 \mathrm{H}_{2} \mathrm{O}$ and $\mathrm{RuCl}_{3} \cdot 3 \mathrm{H}_{2} \mathrm{O}$ with variable $\mathrm{x}_{\mathrm{Ru}}$ (where $\mathrm{x}_{\mathrm{Ru}}$ is considered as $\mathrm{n}_{\mathrm{mol} \mathrm{Ru}} /\left(\mathrm{n}_{\mathrm{mol} \mathrm{Ru}}+\mathrm{n}_{\mathrm{mol} \mathrm{Co}}\right)$ by aqueous sodium borohydride $\left(\mathrm{NaBH}_{4}\right)$. [21]

Cobalt borate $\left(\mathrm{Co}\left(\mathrm{BO}_{2}\right)_{2}\right)$ reference sample was obtained by precipitation of a $\mathrm{BO}_{2}^{-}$containing aqueous solution with $\mathrm{CoCl}_{2} \cdot 6 \mathrm{H}_{2} \mathrm{O}$ as previously reported in [20]. Cobalt boride $\left(\mathrm{Co}_{\mathrm{x}} \mathrm{B} \mathrm{x}=1,2\right)$ and $\mathrm{RuO}_{2}$ reference samples were purchased from Sigma Aldrich and used as received.

\subsection{Nanostructural and chemical characterization}

For the Electron Microscopy studies, powder samples were impregnated on a copper grid coated with a holey-carbon film. The studies were performed using several microscopes:

A JEOL JEM 2010F Scanning electron transmission FEG (Field Emission Gun) microscope, equipped with a HAADF detector and an imaging filter from Gatan GIF2000. For the Spectrum Imaging (SI) mode, a $0.5 \mathrm{~nm}$ beam with a current of $0.1-0.3 \mathrm{nA}$ scanned along a sample regions was used. The HAADF signal was also simultaneously collected at each point within the scanned region.

A FEI FEGTEM Tecnai G2 F30 S-Twin, equipped with a HAADF detector from Fischione Instruments, an SDD X-Max energy-dispersive X-ray spectrometer (EDXS) detector from Oxford Instruments and an image filter Quantum 96 from Gatan.

Samples for 3D characterization by Electron Tomography were prepared by depositing a small amount of the catalyst powder onto a holey carbon film supported by a 300 mesh copper tomography grid. Tomographic tilt-series in HAADF-STEM mode were acquired using a JEOL JEM 2010F electron microscope operated at $200 \mathrm{kV}$ using a Fischione Ultra-Narrow Gap tomography holder. Series of images of Ru-Co-B $\left(\mathrm{x}_{\mathrm{Ru}}=0.13\right)$ sample were acquired over a wide angular range (from $-70^{\circ}$ to $+70^{\circ}$ ) at tilt increment of $2^{\circ}$ using a magnification of 600,000 times. After data acquisition all images were aligned with respect a common origin and tilt axis using Inspect 3D software (FEI). In the next step 3D reconstruction were computed using the simultaneous iterative reconstruction technique (SIRT), which constrains the reconstructed 
volume to best match the original images when reprojected back along the original tilt directions. Voxel projections and surface rendering were undertaken using Amira 3.1 software. XAFS measurements were performed at the Swiss Norwegian Beam Line (SNBLBM01B) of the European Synchrotron Radiation Facility (ESRF, Grenoble, France). The spectra were obtained at room temperature at the Co K-edge (7709 eV) and Ru K-edge (22117 $\mathrm{eV}$ ) in the transmission mode with cellulose dilution. Co and $\mathrm{Ru}$ metal foil were used as reference for energy calibration. Reference $\mathrm{RuO}_{2}, \mathrm{Co}\left(\mathrm{BO}_{2}\right)_{2}$, cobalt boride $\left(\mathrm{Co}_{\mathrm{x}} \mathrm{B}\right)$ and metal foils were used as standards for oxidation state estimation. Data treatment was performed with ATHENA and ARTHEMIS codes [22].

Magnetic measurements were performed using a Quantum Design SQUID Magnettometry. The diamagnetic contribution corresponding to the sample holder system has been previously measured. The samples were measured as powders, slightly compacted inside the sample holder.

\section{Results}

\subsection{Nanostructure and particle size}

Figure 1 shows a representative TEM micrograph and a graphic representation of the nanostructure and composition of the Co-Ru-B-O series (except for Ru-B-O sample) as we previously reported [21]. Samples show a complex nanostructure in which phases with different density are involved. For this type of system the use of HAADF-STEM imaging technique is very useful, because signal intensity is proportional to $Z^{3 / 2} . t$ (where $Z$ is the atomic number and $t$ is sample thickness). These also-called Z-contrast images permit to distinguish the nanoparticles from the low $\mathrm{Z}$ matrix. Moreover, by using a series of HAADF-STEM images recorded at different tilt angles from $-70^{\circ}$ to $70^{\circ}$, an Electron Tomography can be obtained to get information about 3D nanostructure and phases' distribution [23]. Figure 2.a shows a representative $\mathrm{Z}$-contrast image of the $\mathrm{x}_{\mathrm{Ru}}=0.13$ sample acquired at $200 \mathrm{kV}$. Small nanoparticles 
can be seen (inset in Figure 2.a) also forming bigger spherical 20-40 nm particles. For the rest of the samples, Z-contrast images show a similar nanostructure. Figure 2.b shows a tomographic reconstruction (volume of $\sim 500 \mathrm{~nm}^{3}$ ) obtained from the tilt series of images such as that shown in (a). The voltex visualisation of the three-dimensional shape was optimized to fit the outer shape. In Figure 2.c is presented an orthoslice extracted from the reconstructed volume shown in Figure 2.b. The intensities of the orthoslice, which are proportional to the local density of the sample, show that density is inhomogeneous. Image intensities are brighter on surface (see white arrows) in comparison to the darker intensities inside suggesting that Ru accumulates on surface. A more detailed Electron Tomography study is performed on a spherical grain of around $30 \mathrm{~nm}$ diameter size and is shown in Figure 2.d (below). The reconstructed volume is shown in Figure 2.e, where low $\mathrm{Z}$ zones are colored in green (veil), high $\mathrm{Z}$ (metallic) nanoparticles are in brilliant blue, and matrix is in dark blue. An internal mesoporous structure is found with a pore diameter of ca. $5 \mathrm{~nm}$. The internal porosity is evident from the axial slice through the reconstruction displayed in Figure 2.f. A movie (in mpg format as supporting information) showing the full dynamic tomogram is available as a web enhanced object, where the presence of the veil is also very clear. It is clear from the reconstruction that small particles are completely embedded within the porous matrix.

The study of particle size is a difficult and controversial task for this type of materials because the involved phases are amorphous or nano-crystalline. However, the estimation of particle size is essential to understand catalytic and magnetic behavior. High Resolution Electron Microscopy (HREM) is well known to provide information about particle size and crystalline phases. The series was studied by HREM but unfortunately samples were not stable under the electron beam, changing in size and crystallizing. Instead, the intensity profile (signal intensity as a function of probe position) of several Z-contrast images has been analyzed to determine an approximate size of the brighter cores, corresponding to $\mathrm{Co} / \mathrm{Ru}$ rich nanoparticles. Figure 3 shows the variation the particle size as a function of Ru content. Average size is almost constant 
and around $1.5 \mathrm{~nm}$ for the Co-containing materials and increases to $3 \mathrm{~nm}$ for the Ru-B-O sample.

\subsection{Chemical characterization}

Due to the amorphous character of the matrix and the small size of the nanoparticles embedded in it, the study of involved phases requires the use of XAS and EELS techniques. Both techniques permit to study electronic states: EELS gives information with lateral resolution while XAS senses an average of the whole sample. In this sense both EELS and XAS are complementary.

The XANES (X-Ray absorption near edge structure) region of the XAS spectra contains information of oxidation states and provides electronic information of the absorbing atom and its environment. Although multiple scattering calculations can be carried out to simulate the XANES spectra, a fingerprinting method can be used by the comparison of results with reference samples [24]. Figure 4.a shows the Co K-edge for the Co-Ru-B-O series in comparison with references (Co foil, $\mathrm{Co}\left(\mathrm{BO}_{2}\right)_{2}$ and cobalt boride). The spectra show two remarkable features labeled $\mathrm{A}(\sim 7713 \mathrm{eV})$ and $\mathrm{B}(\sim 7725 \mathrm{eV})$ with different nature [24]. The $\mathrm{A}$ feature, or pre-edge, has a low intensity because of its forbidden nature (a d-level as final state). The B transition has a p-level as final state and is normally called "white line". Meitzner et al. related the white line intensity in the $5 \mathrm{~d}$ metal series with the empty states above the Fermi level, showing that the white line decreases when less empty levels are available [26]. Also Hlil et al. described a reciprocal relationship between the pre-edge and the white line along the series of variable composition for the $\mathrm{Co} / \mathrm{Pt}$ system [27]. In our case, by comparison the spectra of the series with references, a decrease in the intensity of A and an increase of B is observed with Ru content. These features indicate a change in the empty levels available with respect Co foil. That could be explained by the presence of Co-B-O and Co-Ru based phases. The comparison of $E_{0}$ along the series (obtained from the derivative of the Co K edge, Figure 4.b) shows that most Co remains in metallic state, independently of $\mathrm{Ru}$ content. 
The $\mathrm{Ru} \mathrm{K}$-edge XANES spectra are plot together with $\mathrm{Ru}$ foil and $\mathrm{RuO}_{2}$ as reference samples in Figure 4.c. The comparison of prepared samples with $\mathrm{Ru}$ foil shows similar features but less intense. Similar results were reported by $\mathrm{O}^{\prime}$ Grady et al., indicating that $\mathrm{Ru} \mathrm{K}$-edge is not so sensitive to changes in alloys with other metals [28]. Also it is clearly observed that these features are damped in the NPs samples respect to the metal foil. This effect is due to structural disorder in the samples [29]. The comparison of $\mathrm{E}_{\mathrm{o}}$ (Figure 4.d) shows that along the series, $\mathrm{Ru}$ is mostly present in metallic state as occurs with Co.

As mentioned above, XAS provides "structure-average" information of the same absorber atom. If the absorber atoms adopt several configurations, individual local structural information is obtained as a weighted average of all configurations. In this case EELS studies are essential to get chemical information in the nanoscale. The study of ELNES (Electron Energy Loss Near Edge Structure) can provide information on the local coordination and oxidation states. The use of STEM mode with small probe size (less than $1 \mathrm{~nm}$ ) permits to get this information with a very high lateral resolution [30]. Furthermore, this technique is especially suitable for the characterization of light elements. The use of EDX measurements in parallel with EELS in STEM mode permits also to get elemental maps by suitable quantification of the spectra.

For the $\mathrm{x}_{\mathrm{Ru}}=0$ sample, the ELNES study of the B-K, O-K and Co- $\mathrm{L}_{2,3}$ edges in comparison with references (finger-printing) permitted previously the elucidation of composition in the nanoscale [20]. Similar methodology was employed in this work to study the elemental distribution and chemical composition and of the rest of Co- containing materials of the series. For these samples EELS and EDX spectra were simultaneously measured with high lateral resolution and $\mathrm{B}, \mathrm{O}, \mathrm{Co}$ and Ru maps were obtained using the Spectrum-Imaging method [30]. Figure 5 shows the maps obtained for the $\mathrm{x}_{\mathrm{Ru}}=0.13$ sample. Co elemental map shows a heterogeneous distribution throughout the area, with presence of nanoparticles very rich in it. The Ru map also shows cores very rich in ruthenium located preferentially on surface, in agreement with the tomography result. In both maps, small metallic nanoparticles are well distinguished from the matrix and the approximate size obtained by the study of HAADF images (section 3.1) is 
confirmed. Oxygen and boron maps show a heterogeneous distribution of both elements. Elemental maps obtained for the $\mathrm{x}_{\mathrm{Ru}}=0.7$ sample (not shown), indicate also a heterogeneous distribution of the elements in the nanoscale.

To get information about the phases in the nanoscale, EELS spectra measured along $16 \mathrm{~nm}$ lines using a $0.5 \mathrm{~nm}$ probe size were studied. $\mathrm{B}$ and $\mathrm{O} \mathrm{K}$-edge, $\mathrm{Ru} \mathrm{M}_{4,5}$-edge, and $\mathrm{Co}_{2,3}$ - edges were recorded for the $\mathrm{x}_{\mathrm{Ru}}=0.13$ and $\mathrm{x}_{\mathrm{Ru}}=0.7$ samples. O-K edges, not shown, presented low signal intensity. Representative spectra on five positions (a-e; f-j) are shown in Figure 6. The study of the B-K edge on both samples (Figure 6.a and 6.c) and the comparison with edges measured for reference materials from our previous work shows contributions of $\mathrm{Co}_{\mathrm{x}} \mathrm{B}$ (cobalt boride), $\mathrm{B}_{2} \mathrm{O}_{3}$, Co-B-O phases [20]. For the $\mathrm{x}_{\mathrm{Ru}}=0.13$ sample there is a major contribution of $\mathrm{Co}_{\mathrm{x}} \mathrm{B}$ (points $\mathrm{a}, \mathrm{b}$ and d), with minor presence of $\mathrm{B}_{2} \mathrm{O}_{3}$, and Co-B-O (points $\mathrm{c}$ and d respectively). The shape of $\mathrm{B}-$ $\mathrm{K}$ edge in point $\mathrm{a}, \mathrm{b}$ and $\mathrm{d}$, is also consistent with the presence of interstitial $\mathrm{B}$ [20]. On the contrary, for the $\mathrm{x}_{\mathrm{Ru}}=0.7$ sample there is a high contribution of Co-B-O (points $\mathrm{f}, \mathrm{h}, \mathrm{i}$ ) and $\mathrm{Co}_{\mathrm{x}} \mathrm{B}$ and $\mathrm{B}_{2} \mathrm{O}_{3}$ (points $\mathrm{j}$ and $\mathrm{g}$ respectively) in a lesser extent. The shape of $\mathrm{Ru} \mathrm{M}_{4,5}$-edges was compared with reference samples studied in another paper [21]. These edges are typical of metallic state for both samples (Figure 6.b. and 6.d) with a small contribution of oxidized ruthenium.

The intensities of $\mathrm{Co}-\mathrm{L}_{2,3}$ edges resonances (white line); correspond to a dipolar transition $\left(2 p_{1 / 2} \rightarrow 3 d\right.$ and $\left.2 p_{3 / 2} \rightarrow 3 d\right)$ which reflect the occurrence of unoccupied states in the $d$ band. The $\mathrm{L}_{3} / \mathrm{L}_{2}$ area ratio depends on chemical composition, structure, formation of alloys, crystal field, particle size, and magnetic moment [31]. For this reason, the exact interpretation of the $L_{3} / L_{2}$ ratio is a difficult task. As an approximation $\mathrm{L}_{3} / \mathrm{L}_{2}$ measurements can be compared with those obtained with reference materials to get an idea of the oxidation state as we did in a previous paper [20]. In this work this ratio was approximated by the ratio of intensities of the $\mathrm{L}_{2}$ and $\mathrm{L}_{3}$ white lines. In Figure 7 the ratio was calculated as a function of the probe position. For the $\mathrm{x}_{\mathrm{Ru}}=0.13$ sample, $\mathrm{L}_{3} / \mathrm{L}_{2}=1.4$ was obtained (at $7 \mathrm{~nm}$ ) indicating that cobalt is in reduced form, as $\mathrm{Co}^{0}$ or $\mathrm{Co}_{\mathrm{x}} \mathrm{B}$. Despite this, most positions show a ratio around 1.5. This could indicate presence 
of cobalt in Co-B-O and Co-Ru phases. However, the analysis of B K-edges indicates low contribution of B-O. For this reason, the increase in the $\mathrm{L}_{3} / \mathrm{L}_{2}$ can be explained as due to the presence of $\mathrm{Co}-\mathrm{Ru}$ phases with a small contribution of $\mathrm{Co}\left(\mathrm{BO}_{2}\right)_{2}$ on surface. For the $\mathrm{x}_{\mathrm{Ru}}=0.7$ sample, most points show a $\mathrm{L}_{3} / \mathrm{L}_{2}$ ratio around 1.75 , in the range of cobalt oxides $(\mathrm{CoO}$ and $\mathrm{Co}_{3} \mathrm{O}_{4}$ ). The study of $\mathrm{B}$ and $\mathrm{O} \mathrm{K}$-edges showed that oxygen is preferentially bound to boron. Furthermore, for this sample the contribution of $\mathrm{Co}\left(\mathrm{BO}_{2}\right)_{2}$ phases is negligible, as previously shown in our previous XPS measurements, which means that the presence of some Co-O bonds forming $\mathrm{CoO}$ cannot be disregarded [21]. In this sample the increase of the $\mathrm{L}_{3} / \mathrm{L}_{2}$ ratio could be attributed both to the presence of some $\mathrm{CoO}$ and to the formation of $\mathrm{Co}-\mathrm{Ru}$ bonds. The presence of different chemical environments for cobalt, one with a metallic character $(\mathrm{Co}, \mathrm{Co}-$ $\left.\mathrm{Ru}, \mathrm{Co}_{\mathrm{x}} \mathrm{B}\right)$ and other oxidized $\left(\mathrm{Co}\left(\mathrm{BO}_{2}\right)_{2}, \mathrm{CoO}\right)$ are in agreement with the trend observed in the Co-K edge along the series (Figure 4).

\subsection{Formation of Co/Ru solid solutions}

Co-Ru bulk phase diagram was studied previously and shows that at room temperature, Co and $\mathrm{Ru}$ form solid solutions for the whole range of composition [32]. Ru incorporates in the hcp Co lattice and the lattice parameters follow a linear relationship with $\mathrm{Ru}$ content. The behavior of Co-Ru samples in the nanoscale does not necessarily obey the phase diagram but it gives an idea of the type of interactions between both atoms. For the herein discussed materials, the study of the formation or not of a solid solution is not simple. Structure and composition vary in the nanoscale as demonstrated by EELS and EDX elemental maps (Figure 5) discussed in previous sections. Furthermore, changes observed in the Co $\mathrm{K}$ and $\mathrm{L}_{2,3}$ edges for the $\mathrm{Ru}$ containing samples would be consistent with the formation of Co-Ru bonds. To test the hypothesis of the formation Co-Ru solid solutions (denoted as $\mathrm{Co}_{\mathrm{x}} \mathrm{Ru}_{(1-\mathrm{x})}$ ), the EXAFS region of the XAS spectra was analyzed. From the fitting of the EXAFS oscillations, information about the neighboring atoms, coordination number and distances between neighbors can be obtained. Tables 1 and 2 show the parameters (distances and coordination numbers respectively) obtained 
from the fitting of the EXAFS oscillations from Co and Ru K-edges. Metal-boron and metaloxygen distances are indistinguishable with this technique due to the closer atomic number and similar atomic factors. The distances are similar for $\mathrm{Ru}-(\mathrm{B} / \mathrm{O})$ and $\mathrm{Co}-(\mathrm{B} / \mathrm{O}) \quad(\sim 2 \AA)$ independently of composition. As the first shell can be composed by three elements, O/B, Co and $\mathrm{Ru}$, the inclusion of all these parameters increases the uncertainties in the results. This situation is more favorable for $\mathrm{Ru}$ because the $\mathrm{k}$-space region to fit is larger than Co case. Even though the uncertainties vary from $\mathrm{Co}$ to $\mathrm{Ru}$, the intervals overlap. The coordination numbers $(\mathrm{CN})$ in Table 2 exhibit a drastic reduction respect to bulk results. This result can be explained due to disorder and surface effects [33]. The amorphous/nanocrystalline character of samples and the appearance of dangling bonds on such small nanoparticles (with high surface to bulk atoms ratio) contribute to the drastic decrease in $\mathrm{CN}$.

\subsection{Magnetic behaviour}

Figure 8.a shows the thermal dependence of the magnetization (M) measured with a 5T applied field for the Co-Ru-B series. The $\mathrm{x}_{\mathrm{Ru}}=1$ sample exhibits a diamagnetic behavior with no change in Ms (Saturation magnetization) with temperature, while the rest of the series (Co-containing samples) exhibit a ferromagnetic behavior. For the latter, the study of the derivate of these curves (Figure 8.b), indicates the presence of two magnetic phases: one with a low Curie point (below $50 \mathrm{~K}$ for samples $\mathrm{x}_{\mathrm{Ru}} 0,0.13$ and 0.5 and around $15 \mathrm{~K}$ for sample $\mathrm{x}_{\mathrm{Ru}} 0.7$ ), and other that exhibits a ferromagnetic behavior up to room temperature. The ferromagnetic behavior is also evidenced by the hysteresis loops (at different temperatures) shown in Figure 9.a for the $\mathrm{x}_{\mathrm{Ru}} 0.13$ sample. All the Co-containing samples show hysteresis loops up to room temperature and magnetization does not even saturate for fields up to 5T. The plot of the Hc (coercitive field) as a function of temperature (Figure 9.b) supports the hypothesis of the two magnetic phases. Hc exhibits a sharp decrease from 5 to $50 \mathrm{~K}$ and an almost linear dependence with temperature. 
Figures 10.a and 10.b show the variation of $\mathrm{Hc}$ and Ms (Saturation magnetization) respectively at 5 and $300 \mathrm{~K}$ with the $\mathrm{Ru}$ content. The addition of a small amount of $\mathrm{Ru}\left(\mathrm{x}_{\mathrm{Ru}}=0.13\right)$ produces an increase in the $\mathrm{Hc}$ respect to Co-B-O sample, which indicates stronger anisotropy fields. Also there is an increase in the Ms from $\mathrm{x}_{\mathrm{Ru}} 0$ to $\mathrm{x}_{\mathrm{Ru}}$ 0.13. Further increase in $\mathrm{Ru}$ content promotes a decrease in $\mathrm{Hc}$ and Ms.

\subsection{Nanoparticles, amorphous matrix and ferromagnetic behavior: Structure-performance relationship.}

Magnetic measurements reveal the presence of a complex magnetic structure in which phases with different behavior coexist. For such system magnetic behavior depends not only on the individual components but also on the interaction between the different phases, i.e. particleparticle interactions transmitted by the matrix, and particle-matrix interactions.

As discussed in previous sections, for the Co containing samples of the series, the structure is characterized by the formation of $20-40 \mathrm{~nm}$ particles which include even smaller $(2 \mathrm{~nm})$ metallic nanoparticles embedded in an amorphous matrix of $\mathrm{Co}_{\mathrm{x}} \mathrm{B}$ (cobalt borides), $\mathrm{B}_{2} \mathrm{O}_{3}$, cobalt oxides and Co-Ru-B-O phases. All the structure is surrounded by a $\mathrm{Co}\left(\mathrm{BO}_{2}\right)_{2}$ veil. $\mathrm{B}_{2} \mathrm{O}_{3}$ and $\mathrm{Ru}-\mathrm{O}$ phases are non-magnetic. Co oxides are antiferromagnetic in bulk, with a Neel temperature (TN) is $291 \mathrm{~K}$ and $40 \mathrm{~K}$ for $\mathrm{CoO}$ and $\mathrm{Co}_{3} \mathrm{O}_{4}$, respectively. $\mathrm{Co}_{3} \mathrm{~B}$ and $\mathrm{Co}_{2} \mathrm{~B}$ phases are ferromagnetic (Curie temperatures of $747 \mathrm{~K}$ and $433 \mathrm{~K}$, respectively) and an amorphous Co-B alloy has been also reported to be ferromagnetic at room temperature [34]. For this reason $\mathrm{Co}_{\mathrm{x}} \mathrm{B}$ phases are also expected to be ferromagnetic.

As concerns to the small (less than $2 \mathrm{~nm}$ ) nanoparticles, they are mainly composed of Co, $\mathrm{Co}_{\mathrm{x}} \mathrm{Ru}_{(1-\mathrm{x})}$ or $\mathrm{Ru}$. The latter is non-magnetic, therefore its contribution should not be considered. Co is a well-known ferromagnetic material with $1388 \mathrm{~K}$ Curie temperature. Isolated $2 \mathrm{~nm}$ Co nanoparticles are superparamagnetic at temperatures around 10K [35]. Co-Ru nanoparticles (2 $\mathrm{nm}$ ) have been reported to be ferromagnetic below $2 \mathrm{~K}$ with high values of the coercive field, 
(1000 Oe -8000 Oe), whereas a superparamagnetic behavior is observed above this temperature [36].

In our case, Co-Ru-B-O samples exhibit ferromagnetism up to room temperature, with coercive field values ranging between 50 and 80 Oe. Taking into account the small size of the metal-rich nanoparticles, the origin of this behavior arises mainly from $\mathrm{Co}_{\mathrm{x}} \mathrm{B}$ phases in the matrix. By decreasing the temperature to $50 \mathrm{~K}$, the coercive field increases as expected for a ferromagnetic material. However, by a further decrease to $5 \mathrm{~K}$ a drastic hardening is observed. This behavior should be attributed to $\mathrm{Co}$ or $\mathrm{Co}_{\mathrm{x}} \mathrm{Ru}_{(1-\mathrm{x})}$ nanoparticles that are blocked at $5 \mathrm{~K}$. By increasing the temperature, these nanoparticles become unblocked and enter into the superparamagnetic regime giving no contribution to the hysteresis.

The evolution of $\mathrm{Hc}$ and Ms with the composition shows that a small addition of Ru increases the anisotropy field, as evidenced by the increase of the coercive field observed at low temperatures in samples $\mathrm{x}_{\mathrm{Ru}} 0.13$ (Figure 10.a). This hardening can be explained by the formation of a $\mathrm{Co}_{\mathrm{x}} \mathrm{Ru}_{(1-\mathrm{x})}$ solid solution. The increase in the $\mathrm{Ru}$ content promotes a softening that is especially evident in the case of $\mathrm{x}_{\mathrm{Ru}}=0.7$ sample. Also higher values of the high field susceptibility are obtained. Simultaneously the magnetization decreases. The above can be interpreted by considering two magnetic contributions from the matrix, $\mathrm{Co}_{\mathrm{x}} \mathrm{B}$ and $\mathrm{CoO}$. For sample $\mathrm{x}_{\mathrm{Ru}}=0.7$ hysteresis loops for temperatures above $50 \mathrm{~K}$ shows low values of the coercive field, being close to zero at room temperature. This behavior can be explained taking into account that the matrix is mainly composed by a $\mathrm{CoO}$ antiferromagnetic phase. As it is well known antiferromagnetic materials are characterized by low magnetization values in combination with high values of the high field susceptibility. The small hysteresis could arise from some clustering of nanoparticles as well as from the $\mathrm{Co}_{\mathrm{x}} \mathrm{B}$ remaining phase. By reducing $\mathrm{Ru}$ content $\left(\mathrm{x}_{\mathrm{Ru}}=0.5\right.$ and $\left.\mathrm{x}_{\mathrm{Ru}}=0.13\right)$, the increase magnetization values as well as a decrease of the high field susceptibility are explained by the increase in the amount of the $\mathrm{Co}_{\mathrm{x}} \mathrm{B}$ with respect to $\mathrm{CoO}$. 


\section{Conclusions}

A series $\mathrm{Co}-\mathrm{Ru}-\mathrm{B}-\mathrm{O}$ ultrafine materials with variable $\mathrm{Ru}$ content previously employed as catalysts for hydrogen generation, were exhaustively studied using microscopies and spectroscopies techniques (HAADF-STEM, electron tomography, EDX, and EELS, with high lateral resolution, and also XAS) and magnetically. Despite the complexity of these materials, the study confirms our previous hypothesis of the formation of very small metallic nanoparticles $\left(\mathrm{Co}, \mathrm{Ru}\right.$ and $\left.\mathrm{Co}_{\mathrm{x}} \mathrm{Ru}_{1-\mathrm{x}}\right)$ of less than $2 \mathrm{~nm}$ size, embedded in an amorphous porous matrix, mainly composed of $\mathrm{Co}_{\mathrm{x}} \mathrm{B}$, and $\mathrm{B}_{2} \mathrm{O}_{3}, \mathrm{Co}-\mathrm{O}$ and $\mathrm{Co}-\mathrm{Ru}-\mathrm{B}-\mathrm{O}$ phases. The ferromagnetic character at room temperature of the Co-containing samples can be explained by the presence of $\mathrm{Co}_{\mathrm{x}} \mathrm{B}$ amorphous phases in the matrix. The hardening observed for $\mathrm{T}<50 \mathrm{~K}$ is due to the presence of metallic magnetic nanoparticles that are blocked. The addition of $\mathrm{Ru}$ to the Co-B-O sample produces also an hardening at low temperature that confirm the formation of $\mathrm{Co}_{\mathrm{x}} \mathrm{Ru}_{(1-\mathrm{x})}$ solid solution, as suggested by the analysis of the EELS and XAS and spectra. Further addition of Ru produces a change in the matrix composition characterized for the reduction of the amount of $\mathrm{Co}_{\mathrm{x}} \mathrm{B}$ and the formation of $\mathrm{CoO}$, an antiferromagnetic phase that explains the magnetic behavior of the $\mathrm{x}_{\mathrm{Ru}}=0.7$ (lower $\mathrm{Hc}$ and high field susceptibility). As a consequence of this study, the issues raised related to structure, chemical composition, and the formation of solid solution were solved, contributing to the comprehension of the nature of metal-metalloid interactions in these controversial nanoalloys.

\section{References}

[1] Andreas Züttel, Andreas Borgschulte and Louis Schlapbach in "Hydrogen as a Future Energy Carrier”. Wiley-VCH, 2008.

[2] Louis Schlapbach, Andreas Züttel, Nature, 2001, 414, 353-358.

[3] G. Moussa, R. Moury, U.B. Demirci, T. Sener, P. Miele, Int. J. Energy Res, 2013, $37,825-842$. 
[4] B.H. Liu, Z.P. Li, J. Power Sources, 2009, 187,527-534. References therein

[5] U.B Demirci, O.Akdim, J. Andrieux, J. Hannauer, R. Chamoun, P.Miele. Fuel Cells, 2010: 3: 335-350. References therein

[6] S.S. Muir, X. Yao. Int J. Hydrogen Energy, 2011; 36: 5983-5997. References therein

[7] E.Y Marrero-Alfonso, J.R. Gray, T.A Davis, M.A. Matthews, Int. J. Hydrogen Energy 32 , 2007, 4723-4730.

[8] C F. Lo, K. Karan, B R. Davis.. Ind. Eng. Chem. Res. 2007, 46, 5478-5484

[9] U.B Demirci, O.Akdim, J. Andrieux, J. Hannauer, R. Chamoun, P.Miele, Sci China Chem, 2010, 53, 1870-1879. References therein

[10] U.B. Demirci, P.Miele, Phys. Chem. Chem Phys, 2010; 12: 14665-14651. References therein

[11] U. B. Demirci andP. MIELE, Phys. Chem. Chem. Phys., 2014, DOI: 10.1039/C4CP00250D.

[12] O. Akdim, U.B. Demirci, D. Muller, P. Miele, Int. J. Hydrogen Energy, 2009, 34, 2631-2637.

[13] H. Li, J. Liao, X. Zhang, W. Liao, L. Wen, J. Yang, H. Wang and R.Wang, J. Power Sources, 2013, 239, 277-283

[14 ] O. Akdim, R. Chamoun, U.B. Demirci, Y. Zaatar, A. Khoury, P. Miele. Int J H Energy, 2011, 36, 14527-14533.

[15] N. Patel, A. Miotello, V. Bello, Appl. Catal B Environ, 2011, 103, 31-38

[16] O.V. Komova, V.I. Simagina, O.V. Netskina, D.G. Kellerman, A.V. Ishchenko, N.A.Rudina, Catal. Today. 138 (2008) 260-265

[17] N. Patel, R. Fernandes, A. Miotello, J. Power Sources, 188, 2009, 411-420. 
[18] S. Carenjco, D. Portehault, C. Boissière, N. Mézailles, C. Sanchez. Chem. Rev. 113, 2013, 7981-8065.

[19] Y. Pei, G. Zhou, N. Luan, B. Zong, M. Qiao, F.Tao, Chem. Soc. Rev., 2012, 41, 81408162

[20] G.M. Arzac, T.C. Rojas, A. Fernández, Chem Cat Chem, 2011, 3,1305-1313.

[21] G.M. Arzac, T.C. Rojas, A. Fernández, Appl. Catal B. Environ, 2012, 128, 39-47

[22] B. Ravel, M. Newville, J. Synchrotron Rad. 2005, 12, 537-541.

[23] L.C. Gontard, R. E . Dunin-Borkowski, D. Ozkaya, J Microscopy, 2008, 232, 248259.

[24] A. Bianconi X-Ray Absorption: Principles, Applications. H. E. Schaefer, Nanostruct.Mater., 1995, 6, 925. Techniques of EXAFS, SEXAFS and XANES, ed. D. C. Konigsberger and R. Prins, John Wiley, New York, 1988, ch. 11,. pp. 573-662.

[25] T.C. Rojas, J.C. Sánchez-López, M.J. Sayagués, E.P. Reddy, A. Caballero, A. Fernández. J. Mater. Chem., 1999, 9, 1011-1017

[26] G. Meitzer, G.H. Via, F.W. Lytle, J.H. Sinfelt, J. Phys. Chem, 96, 1992, 49604694.

[27] E.K. Hlil, R. Baudoing-Savois, J. Phys. Chem. 1996, 100, 3102-3107

[28] W.E. O' Grady, P.L. Hagans, K.I. Pandya, D.L. Maricle, Langmuir, 2001, 17, 3047-3050.

[29] J.J. Rerhr, A.L. Ankudinov, Coordination Chemistry Reviews, 2005, 249, 131-140.

[30] C.Jeanguillaume, C.Colliex, Ultramicroscopy, 1989, 28, 252.

[31] C. Colliex, T. Manoubi, C. Ortiz, Phys Rev B, 44(20), 402-411.

[32] W. Köster, E. Horn, Zeitschrift fur Metallunde, 1952, 43, 12, 444-449

[33] T. Haubold, F. Boscherini, S. Pascarelli, S. Mobilio and H. Gleither, Phil. Mag. (1992) A 66, 591. 
[34] A.B. Davila-Ibánez, J.L. Legido-Soto, J. Rivas, V. Salgueirino, Phys. Chem. Chem. Phys, 2011, 13, 20146-20154

[35] M. Respaud, J. M. Broto, H. Rakoto, A. R. Fert, L. Thomas, B. Barbara, M. Verelst, E. Snoeck, P. Lecante, A. Mosset, J. Osuna, T. Ould Ely, C. Amiens, and B. Chaudret, Phys. Rev. B 57, 2925 (1998)

[36] D. Zitoun, C. Amiens, B. Chaudret, M.C. Fromen, P. Lecante, M.J. Casanove, M. Respaud, J. Phys. Chem B, 2003, 107, 6997-7005.

\author{
Acknowledgements \\ Financial support from MINECO (CTQ2012-32519), CSIC (PIE 201260E006 and \\ 201060E102), Junta de Andalucía (TEP217, PE2012-TEP862) the EC (CT-REGPOT-2011-1- \\ 285895, AL-NANOFUNC) is acknowledged. XAFS experiments were performed on the \\ Swiss-Norwegian Beam Line (SNBL-BM01B) at the European Synchrotron Radiation Facility \\ (ESRF), Grenoble, France. We are grateful to Paula Abdala at ESRF for providing assistance \\ during the measurements (proposal 01-01-894).
}




\section{Figure Captions}

Figure 1- TEM image and graphic showing a general representation of the nanostructure and composition of the Co-Ru-B-O series (except for Ru-B-O sample) as reported in Ref [21].

Figure 2- Above: STEM/HAADF Electron Tomography on the $\mathrm{x}_{\mathrm{Ru}}=0.13$ sample. (a) STEM/HAADF image of the selected zone (b) and (c) Slices of the reconstructed object. Below: Higher magnification STEM/HAADF Electron Tomography on the $\mathrm{x}_{\mathrm{Ru}}=0.13$ sample (d) STEM/HAADF image of a $20 \mathrm{~nm}$ grain. (e) Reconstructed volume (f) Slice of the reconstructed volume.

Figure 3- Particle size determined by the analysis of several STEM/HAADF images as a function of Ru content.

Figure 4- XANES spectra on the Co-Ru-B series in comparison with references (a) Co K-edge (b) Derivate of Co K-edge (c) Ru K-edge (d) Derivate of Ru K-edge.

Figure 5- EDX and EELS elemental maps obtained on a $20 \times 20 \mathrm{~nm}^{2}$ marked zone of the $\mathrm{X}_{\mathrm{Ru}}=0.13$ sample using the SI method.

Figure 6- Selected EELS spectra from different points on a $16 \mathrm{~nm}$ scanned line along the $\mathrm{x}_{\mathrm{Ru}}=0.13$ and 0.7 samples, (a), (c) B K-edge (b), (d) Ru $\mathrm{M}_{4,5}$-edge.

Figure 7- $\mathrm{Co}_{3} / \mathrm{L}_{2}$ ratio as a function of probe position on a $16 \mathrm{~nm}$ scanned line along the $\mathrm{X}_{\mathrm{Ru}}=0.13$ and 0.7 samples.

Figure 8- (a) Magnetization as a function of temperature for the Co-Ru-B series with a $5 \mathrm{~T}$ field. (b) Derivative of (a) respect to $\mathrm{T}$, as a function of temperature.

Figure 9-. (a)Hysteresis loop for the $\mathrm{x}_{\mathrm{Ru}}=0.13$ sample (b) Coercitive field as a function of temperature for the series 
Figure 10- (a) Coercitive field and (b) Saturation magnetization (per gram of Co) as a function of Ru content.

\section{Table Legends}

Table 1. Best fitting parameters (bond length) of the Co and Ru K edges EXAFS oscillations for the Co-Ru-B-O series.

Table 2. Best fitting parameters (coordination numbers) of the Co and Ru K edges EXAFS oscillations for the Co-Ru-B-O series. 


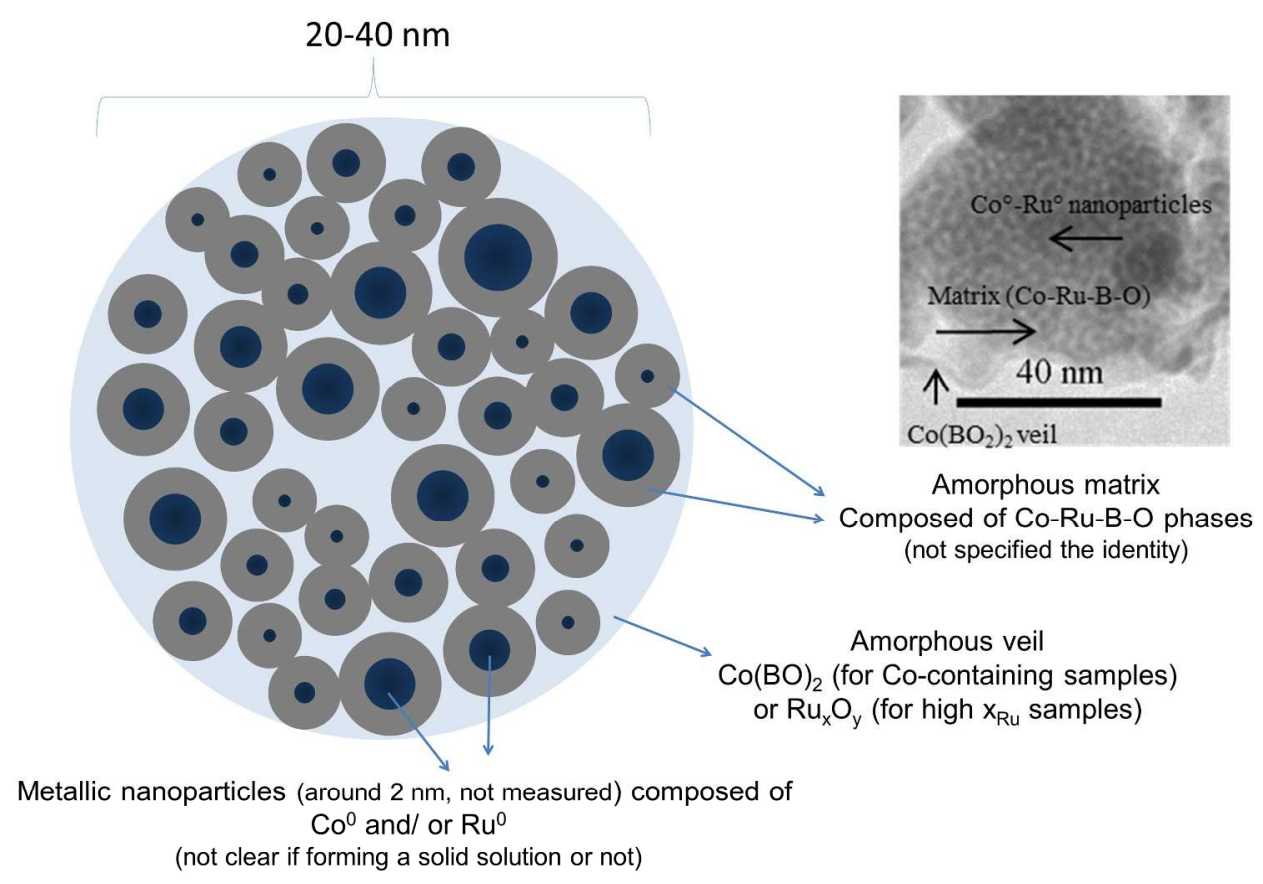

$878 \times 632 \mathrm{~mm}(78 \times 78 \mathrm{DPI})$ 

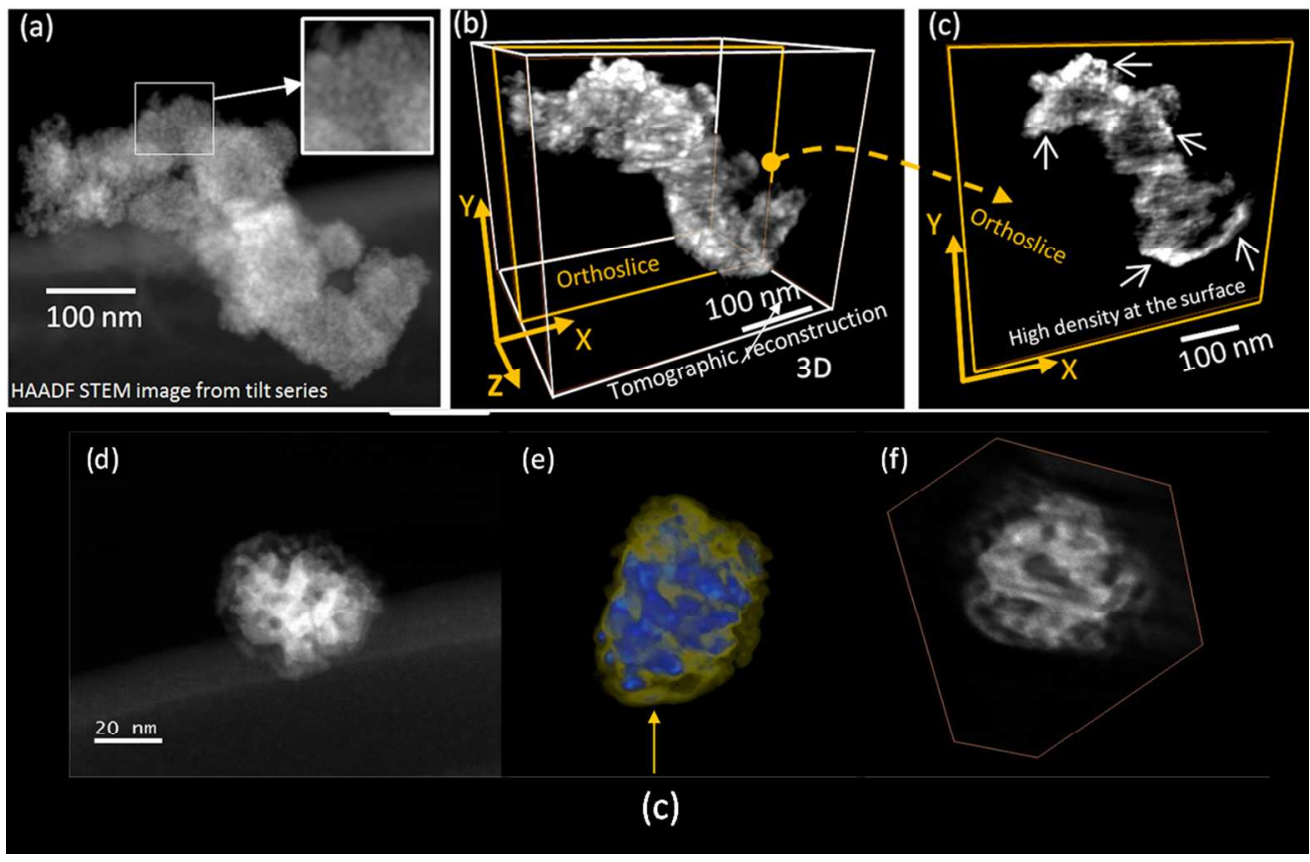

Figure 2- Above: STEM/HAADF Electron Tomography on the $x$ Ru=0.13 sample. (a) STEM/HAADF image of the selected zone (b) and (c) Slices of the reconstructed object. Below: Higher magnification STEM/HAADF Electron Tomography on the $x \mathrm{Ru}=0.13$ sample (d) STEM/HAADF image of a $20 \mathrm{~nm}$ grain. (e) Reconstructed volume (f) Slice of the reconstructed volume. $212 \times 137 \mathrm{~mm}(150 \times 150 \mathrm{DPI})$ 


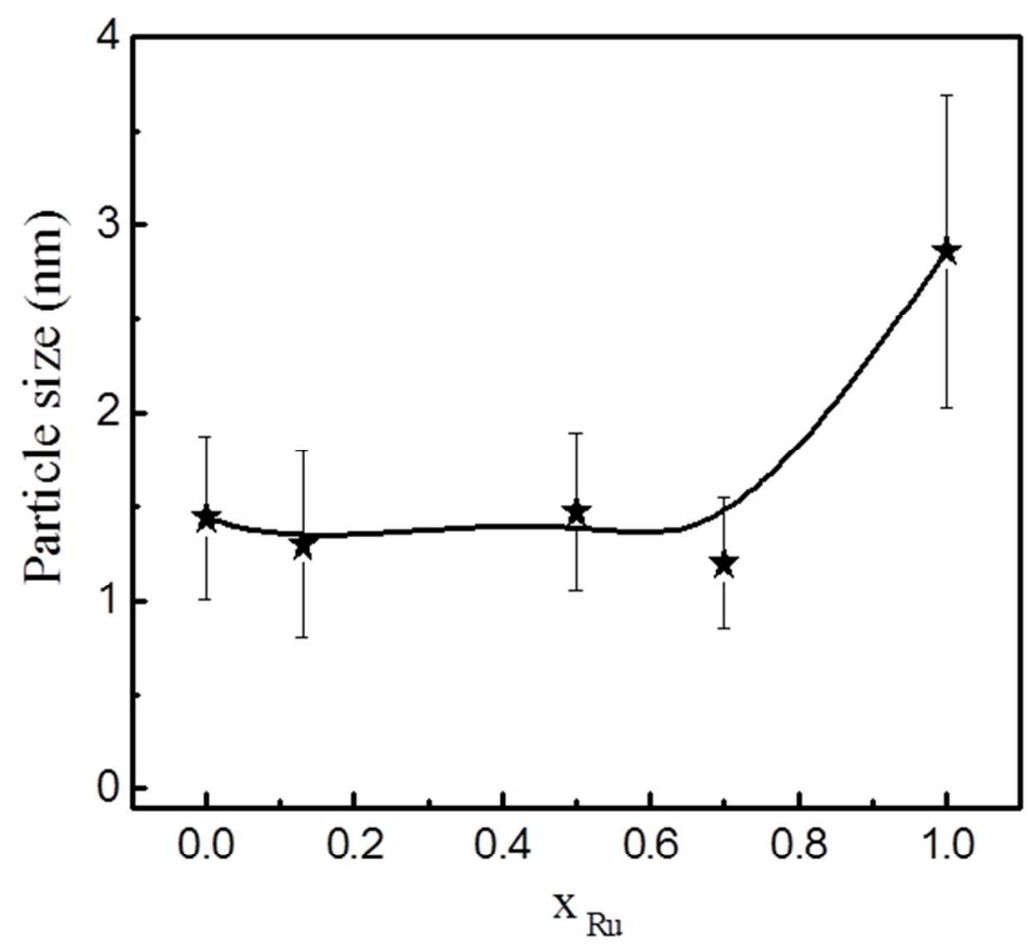

Figure 3- Particle size determined by the analysis of several STEM/HAADF images as a function of Ru content. $122 \times 101 \mathrm{~mm}(150 \times 150 \mathrm{DPI})$ 

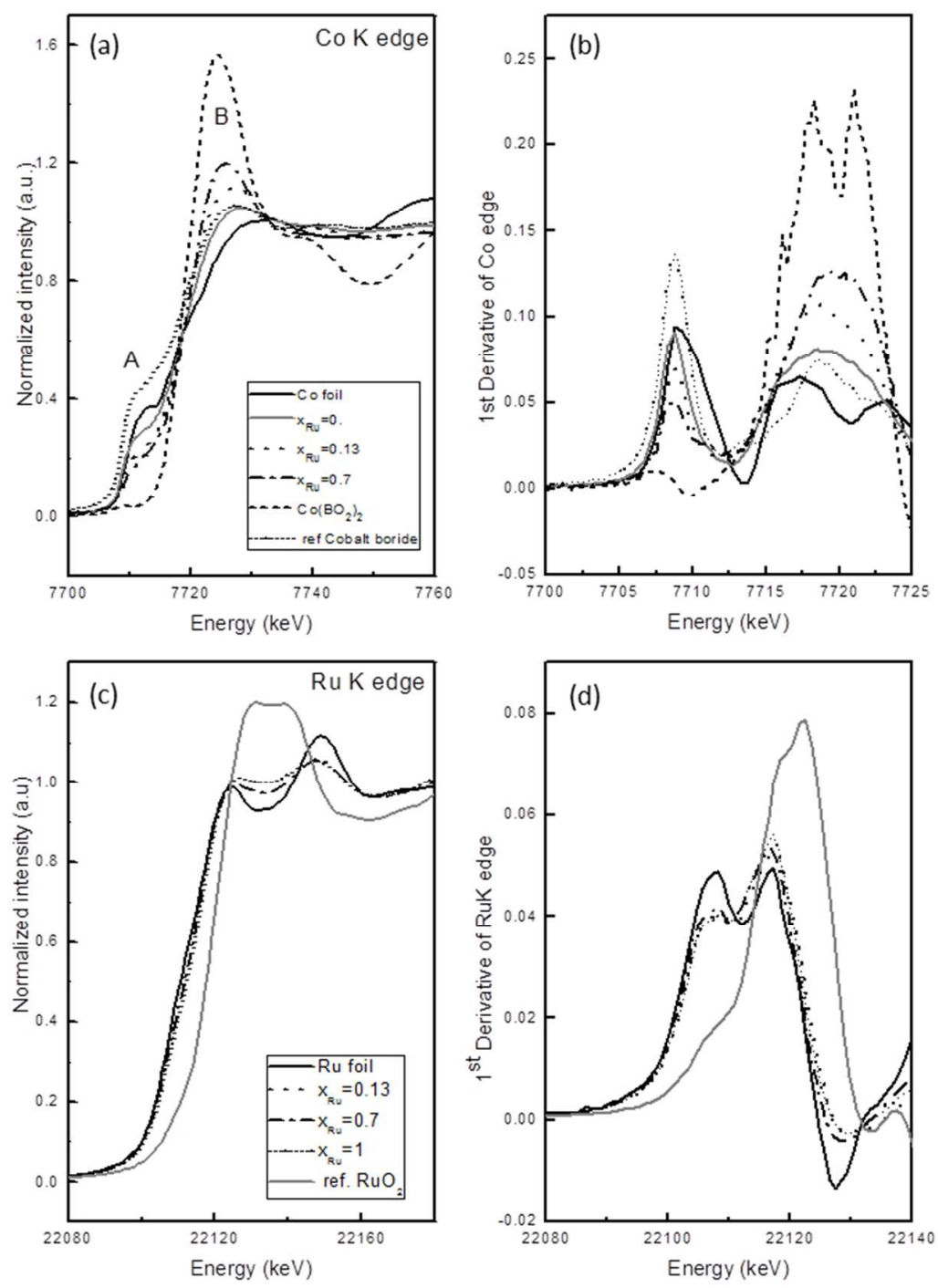

Figure 4- XANES spectra on the Co-Ru-B series in comparison with references (a) Co K-edge (b) Derivate of Co K-edge (c) Ru K-edge (d) Derivate of Ru K-edge. $123 \times 173 \mathrm{~mm}(150 \times 150 \mathrm{DPI})$ 
Figure 5- EDX and EELS elemental maps obtained on a $20 \times 20 \mathrm{~nm}^{2}$ marked zone of the $\mathrm{x}_{\mathrm{RU}}=0.13$ sample using the $\mathrm{SI}$ method.

م)

Co (EDX)

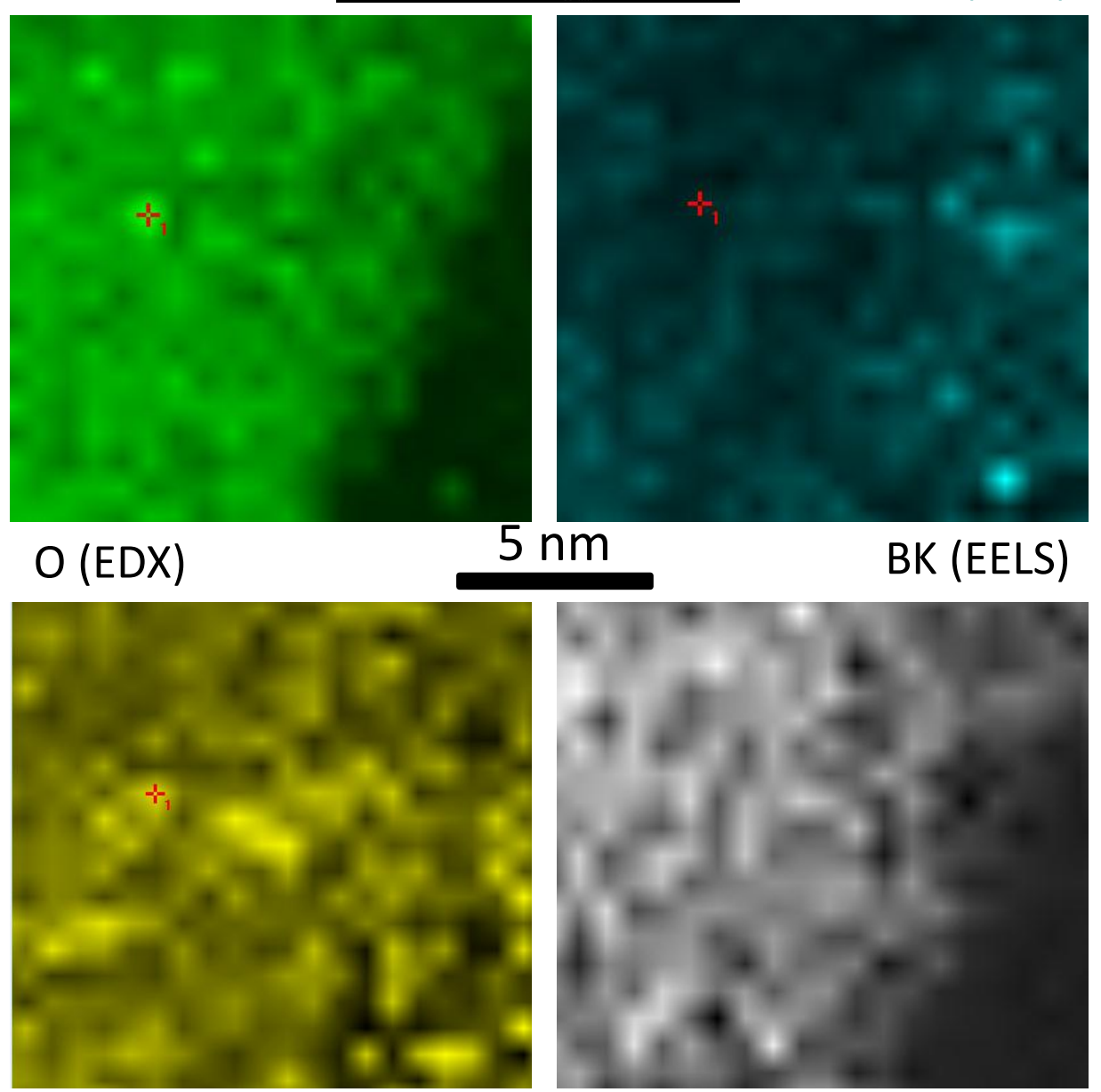


Figure 6
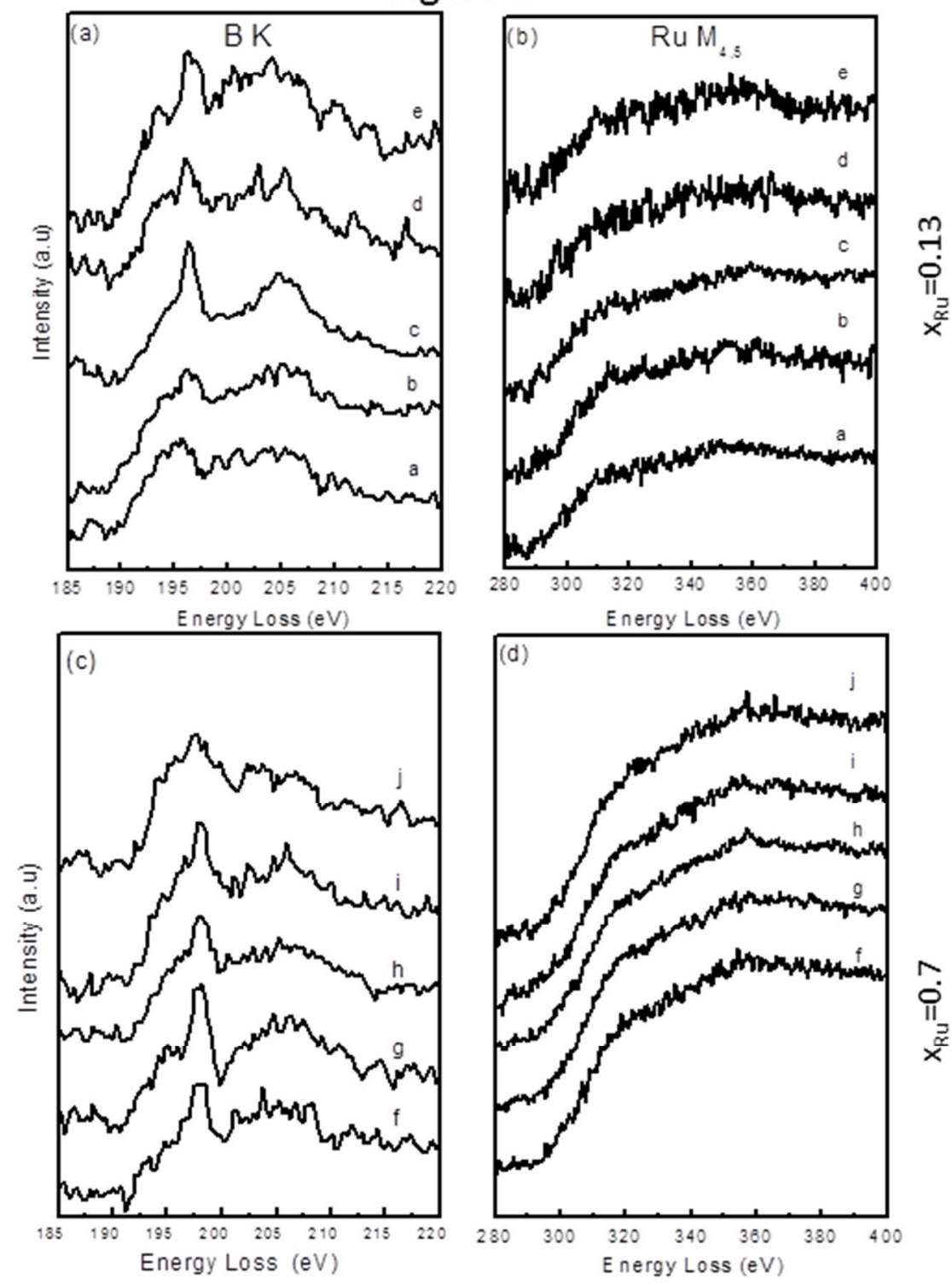

$144 \times 190 \mathrm{~mm}(96 \times 96$ DPI) 


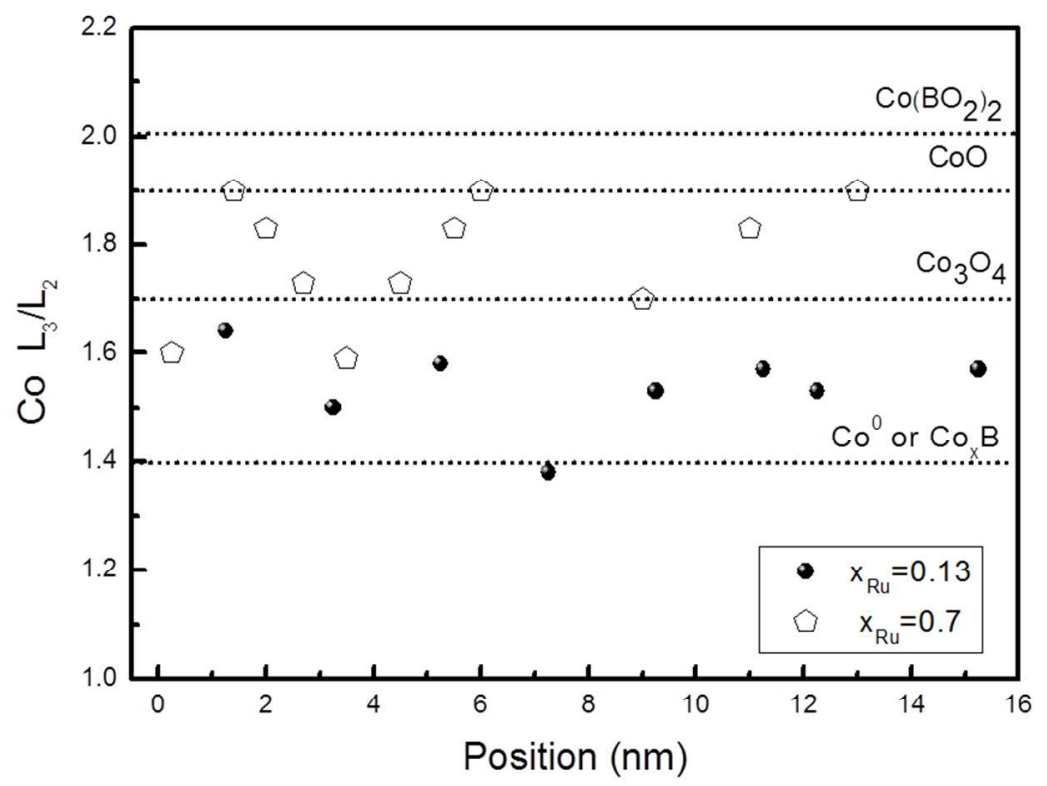

Figure 7- Co $\mathrm{L} 3 / \mathrm{L} 2$ ratio as a function of probe position on a $16 \mathrm{~nm}$ scanned line along the $\mathrm{xRu}=0.13$ and 0.7 samples.

$183 \times 128 \mathrm{~mm}(150 \times 150 \mathrm{DPI})$ 

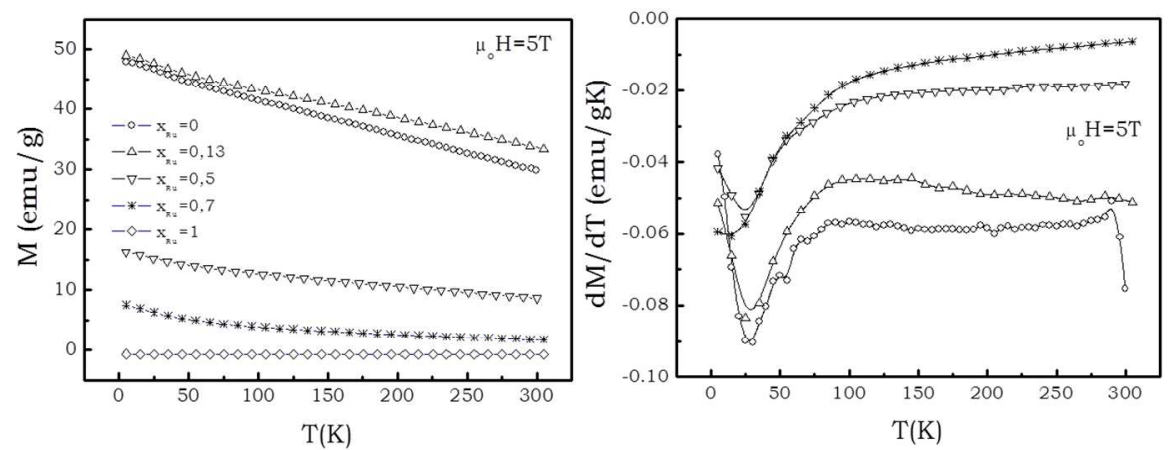

Figure 8- (a) Magnetization as a function of temperature for the Co-Ru-B series with a 5T field. (b) Derivative of (a) respect to $T$, as a function of temperature. $237 \times 91 \mathrm{~mm}(150 \times 150 \mathrm{DPI})$ 


\section{Figure 9}
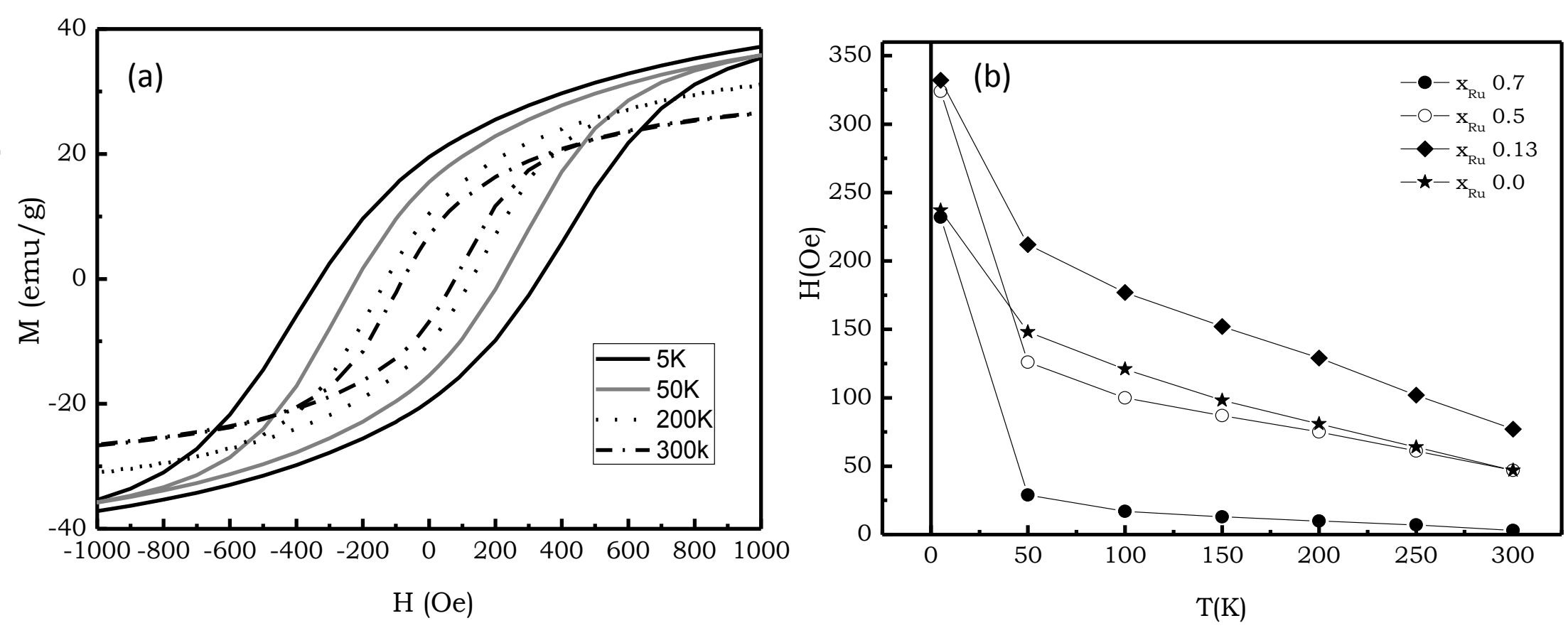

Figure 9-. (a)Hysteresis loop for the $\mathrm{x}_{\mathrm{Ru}}=0.13$ sample (b) Coercitive field as a function of temperature for the series 

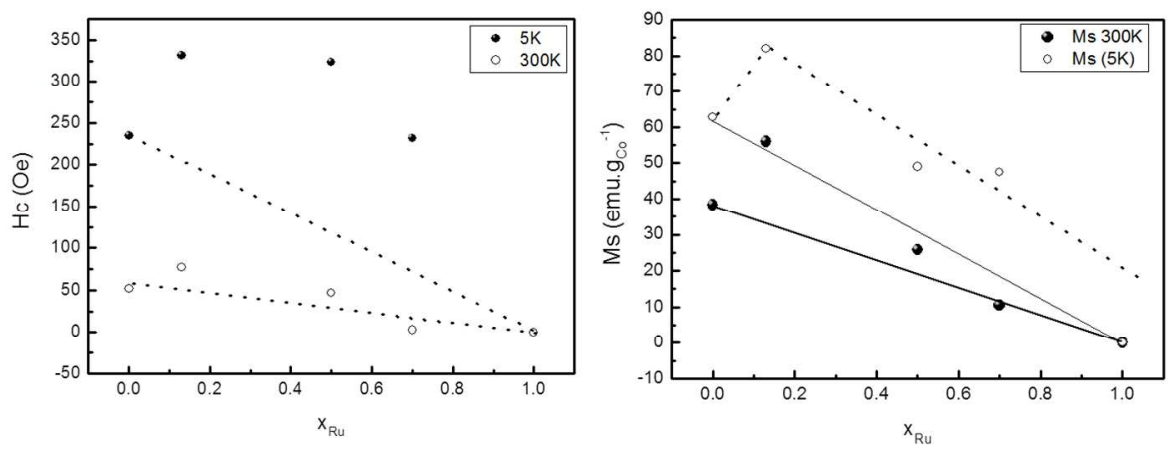

Figure 10- (a) Coercitive field and (b) Saturation magnetization (per gram of Co) as a function of Ru content.

$260 \times 100 \mathrm{~mm}(150 \times 150 \mathrm{DPI})$ 
TABLE 1

\begin{tabular}{|l|r|r|r|r|r|r|r|r|r|r|r|r|r|}
\hline & \multicolumn{9}{|c|}{ Co K-edge } & \multicolumn{3}{c|}{ Ru K-edge } \\
\hline & \multicolumn{2}{|c|}{$\mathrm{d}$ Co-Co } & \multicolumn{2}{c|}{$\mathrm{d}$ Co-Ru } & \multicolumn{2}{c|}{$\mathrm{d}$ Co-(O/B) } & \multicolumn{2}{c|}{$\mathrm{d}$ Ru-Co } & \multicolumn{2}{c|}{$\mathrm{d}$ Ru-Ru } & \multicolumn{2}{c|}{$\mathrm{d}$ Ru-(0/B) } \\
\hline & distance & error & distance & error & distance & error & distance & error & distance & error & distance & error \\
\hline $\mathbf{x}_{\mathrm{Ru}}=\mathbf{0}$ & 2.477 & 0.025 & & & 1.933 & 0.046 & & & & & & \\
\hline $\mathbf{x}_{\mathrm{Ru}}=\mathbf{0 . 1 3}$ & 2.548 & 0.061 & 2.584 & 0.134 & 1.988 & 0.081 & 2.572 & 0.010 & 2.647 & 0.008 & 2.000 & 0.013 \\
\hline $\mathbf{x}_{\mathrm{Ru}}=\mathbf{0 . 7}$ & 2.511 & 0.039 & 2.572 & 0.010 & 2.042 & 0.089 & 2.627 & 0.021 & 2.737 & 0.022 & 2.014 & 0.030 \\
\hline $\mathbf{x}_{\mathrm{Ru}}=\mathbf{1}$ & & & & & & & & & 2.660 & 0.005 & 1.987 & 0.027 \\
\hline
\end{tabular}




\begin{tabular}{|l|r|r|r|r|r|r|r|r|r|r|r|r|r|}
\hline & \multicolumn{9}{|c|}{ Co K-edge } & \multicolumn{5}{c|}{ Ru K-edge } \\
\hline & \multicolumn{1}{|c|}{ CN Co-Co } & \multicolumn{2}{c|}{ CN Co-Ru } & \multicolumn{2}{c|}{$\begin{array}{c}\text { CN Co- } \\
\text { (O/B) }\end{array}$} & \multicolumn{2}{c|}{ CN Ru-Co } & \multicolumn{2}{c|}{ CN Ru-Ru } & \multicolumn{2}{c|}{$\begin{array}{c}\text { CN Ru- } \\
\text { (O/B) }\end{array}$} \\
\hline & CN & error & CN & error & CN & error & CN & error & CN & error & CN & error \\
\hline $\mathbf{X}_{\mathrm{Ru}}=\mathbf{0}$ & 4.6 & 1.5 & & & 1.7 & 0.9 & & & & & & \\
\hline $\mathbf{X}_{\mathrm{Ru}}=\mathbf{0 . 1 3}$ & 1.6 & 1.9 & 1.0 & 2.2 & 1.8 & 1.4 & 1.5 & 0.3 & 4.9 & 0.5 & 1.7 & 0.3 \\
\hline $\mathbf{X}_{\mathrm{Ru}}=\mathbf{0 . 7}$ & 1.0 & 1.8 & 1.1 & 2.1 & 2.9 & 2.7 & 2.7 & 0.8 & 2.2 & 0.4 & 0.9 & 0.3 \\
\hline $\mathbf{X}_{\mathrm{Ru}}=\mathbf{1}$ & & & & & & & & & 5.8 & 0.6 & 1.5 & 0.4 \\
\hline
\end{tabular}

